\title{
Defective mycolic acid biosynthesis in a mutant of Mycobacterium smegmatis
}

\author{
Manikuntala Kundu, Joyoti Basu and Parul Chakrabarti* \\ Department of Chemistry, Bose Institute, 93/1 APC Road, Calcutta 700009, India
}

(Received 11 December 1990; revised 10 April 1991; accepted 4 June 1991)

\begin{abstract}
A mutant of Mycobacterium smegmatis defective in mycolic acid biosynthesis was isolated following chemical mutagenesis. Fatty acids were extracted from the mutant and subjected to structural analysis by thin-layer chromatography and high-performance liquid chromatography (HPLC) of both methyl and $p$-bromophenacyl ester derivatives. Thin-layer chromatography did not show the presence of any fatty acid of $\boldsymbol{R}_{F}$ comparable to that of standard methyl mycolate. The HPLC profile revealed a broad peak in the standard mycolic acid ester region. No characteristic peaks of mycolic acid esters comparable to the wild-type could be resolved. Mass spectral analysis of the HPLC-purified peak demonstrated the presence of shorter-chain fatty acids in the mutant. These data support the idea that the mutant accumulates precursors of mycolic acids and is incapable of carrying out the final conversion to mycolic acids of 60-90 carbon atoms.
\end{abstract}

\section{Introduction}

Mycolic acids are $\alpha$-alkyl- $\beta$-hydroxy fatty acids unique to mycobacteria, nocardiae and corynebacteria (Gray et al., 1982; Kaneda et al., 1988; Minnikin \& Goodfellow, 1980; Minnikin et al., 1980; Qureshi et al., 1978; Ratledge, 1982). They are major cell wall constituents. The number of carbon atoms which make up the mycolic acids varies from 60 to 90 in the genus Mycobacterium (Gray et al., 1982; Kaneda et al., 1988; Minnikin et al., 1980). The basic structure is $\mathrm{R}_{1} \mathrm{CH}(\mathrm{OH}) \mathrm{CH}\left(\mathrm{R}_{2}\right) \mathrm{COOH}$, where $R_{2}$ is a linear alkane $\left(C_{22}-C_{24}\right)$ and $R_{1}$ is a complex structure comprising about 60 carbon atoms and containing different functional groups including hydroxyl, methoxyl, carbonyl and carboxyl groups, cyclopropane rings, methyl branches and carbon double bonds (Steck et al., 1978). Mycolic acids may play an important role in the pathogenicity of mycobacteria, since antituberculous drugs have been shown to inhibit mycolic acid biosynthesis (Takayama et al., 1975), making it important to elucidate the pathway of mycolic acid biosynthesis.

Mycobacterium smegmatis, a rapidly growing cultivable mycobacterium, has been widely used to study mycobacterial metabolism (David, 1977; Matula et al., 1971 ) and the biosynthesis of $\mathrm{C}_{16}-\mathrm{C}_{32}$ fatty acids in $M$. smegmatis has been studied with cell-free extracts (Bloch \& Vance, 1977). Lacave et al. (1990) have also established a cell-free system capable of synthesizing whole mycolic acid in $M$. aurum. The general structure of mycolic acids suggests a Claisen-like condensation reaction between two aliphatic chains. However, the details of the steps involved are still largely unknown (Takayama \& Qureshi, 1984). We have isolated a mutant of $M$. smegmatis defective in synthesis of high-molecularmass $\left(\mathrm{C}_{60}-\mathrm{C}_{90}\right)$ fatty acids. This may be of considerable importance in studying mycolic acid biosynthesis. This is the first report of a mycobacterial mutant defective in mycolic acid synthesis.

\section{Methods}

Isolation of a penicillin-sensitive mutant. Mycobacterium smegmatis $\mathrm{SN}_{2}$ was grown in nutrient broth. Cells grown to early exponential phase were suspended in $50 \mathrm{~mm}$-potassium phosphate buffer, $\mathrm{pH} 6.5$, containing $N$-methyl- $N^{\prime}$-nitro- $N$-nitrosoguanidine (NTG), and incubated at $37^{\circ} \mathrm{C}$ for $1 \mathrm{~h}$. The cells were then harvested, washed to remove NTG under sterile conditions and serially diluted. The diluted suspensions were plated on solid nutrient broth (containing, $1^{-1}:$ beef extract $10 \mathrm{~g}$, peptone $10 \mathrm{~g}, \mathrm{NaCl} 5 \mathrm{~g}$; and $2 \%$, w/v, agar) and incubated for $5 \mathrm{~d}$. Mutants were selected for penicillin sensitivity by replica plating using different concentrations of penicillin $G$ in the growth medium. A penicillin-sensitive mutant was finally picked using a single-colony selection procedure. Biochemical tests specific for $M$. smegmatis (Standard taxonomic tests; US Department of Health and Human Services, 1980) were carried out on the mutant and the wildtype. The arylsulphatase assay was carried out using $p$-nitrocatechol sulphate as a substrate. Catalase activity was measured by using hydrogen peroxide. For the nitrate reduction test, the mutant and the wild-type were grown in nitrate agar (containing $0.1 \% \mathrm{KNO}_{3}$ ) and the change in colour examined after addition of sulphanilic acid to the 
medium. Iron uptake was studied by growing the organism in a medium containing $2.5 \%(\mathrm{w} / \mathrm{v})$ ferric ammonium citrate and following the change in colour of the medium. Arabinogalactan, a characteristic cell wall component of mycobacteria, was isolated and analysed by gasliquid chromatography after hydrolysis as described previously (Kundu et al., 1990).

Isolation of fatty acids. These were isolated using a modification of the method described by Lanéelle et al. (1988). The cells were extracted with chloroform/methanol $(2: 1, \mathrm{v} / \mathrm{v})$, washed with the same solvent, treated with tetrabutylammonium hydroxide overnight at $100^{\circ} \mathrm{C}$, then acidified with $6 \mathrm{M}-\mathrm{HCl}$. Fatty acids were extracted from the reaction mixture using light petroleum (b.p. $40-60^{\circ} \mathrm{C}$ ).

Preparation of fatty acid methyl esters. The extracted fatty acids were methylated using ethereal diazomethane and dried. Methyl esters of fatty acids were spotted on to a silica gel GHL plate (Analtech) and developed with light petroleum/diethyl ether/acetic acid $(9: 1: 0 \cdot 2$, by vol.). Spots on the plates were then visualized either by iodine vapour or by a dichromate and hot sulphuric acid spray.

Preparation of p-bromophenacyl esters of mycolic acids. These were prepared by the method of Butler \& Kilburn (1988). Cells were extracted with $25 \%(\mathrm{w} / \mathrm{v}) \mathrm{KOH}$ in ethanol/water $(1: 1, \mathrm{v} / \mathrm{v})$ at $85^{\circ} \mathrm{C}$. The extract was then treated with chloroform, acidified with concentrated $\mathrm{HCl}$, dried, treated with potassium bicarbonate and again dried. $p$-Bromophenacyl/crown ether mix (Pierce Chemical Co.) was added in 10 -fold molar excess, heated at $85^{\circ} \mathrm{C}$ for $20 \mathrm{~min}$, filtered and the supernatant evaporated under vacuum.

Analysis of p-bromophenacyl esters of mycolic acids. High-performance liquid chromatography (HPLC) was performed on a Waters Associates model $6000 \mathrm{~A}$ liquid chromatograph equipped with a variablewavelength detector (model LC-85B; Perkin-Elmer) measuring absorbance at $254 \mathrm{~nm}$. The mycolic acid $p$-bromophenacyl esters were applied to a $10 \mu \mathrm{m}$ particle size Waters cartridge $\mathrm{C}_{18}$ reverse-phase column equilibrated with $91 \%$ methanol $/ 9 \%$ chloroform. After injection of the sample, the gradient was changed linearly to $30 \%$ methanol $/ 70 \%$ chloroform over a period of $65 \mathrm{~min}$ at a total flow rate of

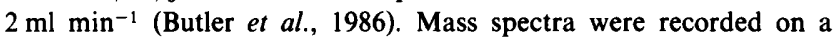
ultrahigh resolution mass spectrometer, MS-50TC (Kratos Analytical Instruments) fitted with a D5-55 data acquisition system. Spectra were obtained at $70 \mathrm{eV}$ ionization potential and $300 \mu \mathrm{A}$ emission current.

\section{Results}

The colonies of the wild-type were rough and wrinkled whereas those of the penicillin-sensitive mutant were smooth and filamentous. Both the wild-type and the mutant satisfied the biochemical tests characteristic of M. smegmatis, i.e. positive for catalase $\left(68^{\circ} \mathrm{C}\right)$, amidase, nitrate reduction, iron uptake and presence of arabinogalactan, and negative for arylsulphatase. The mutant and the wild-type both contained arabinogalactan, a characteristic cell surface component of mycobacteria. Thinlayer chromatography of the methyl esters of fatty acids isolated from both the wild-type and the mutant cells after chloroform/methanol extraction was carried out using standard methyl mycolate from $M$. smegmatis (a generous gift from Dr K. Takayama). No methyl mycolate corresponding to the standard was obtained in the case of the mutant (Fig. 1).

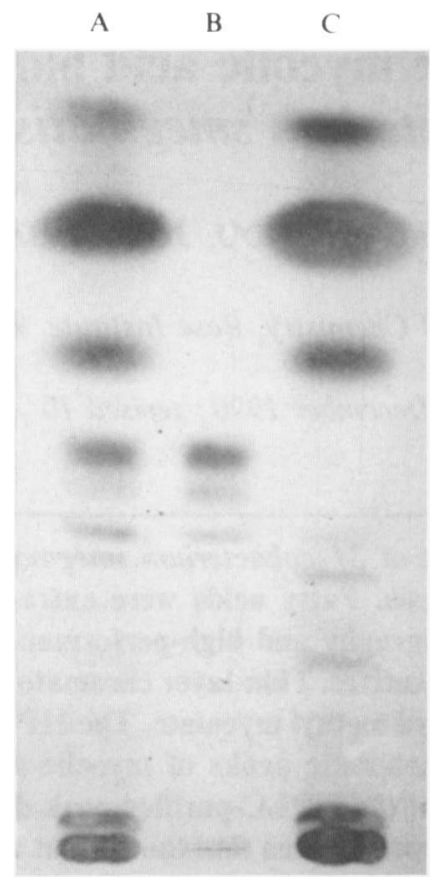

Fig. 1. Thin-layer chromatography of methyl mycolates of wild type M. smegmatis and its mutant: A, wild type; B, standard methyl mycolate; $\mathrm{C}$, mutant.

Preparations of the $p$-bromophenacyl esters of mycolic acids from the mutant and the wild-type were dissolved in a minimum amount of chloroform/methanol $(91: 9$, $\mathrm{v} / \mathrm{v}$ ) and injected into a reverse-phase column as described in Methods. A number of peaks, characteristic of the mycolates from $M$. smegmatis (Takayama \& Qureshi, 1984), were obtained in the case of the wild-type cells. The peaks eluted between 36 and $48 \mathrm{~min}$ at a flow rate of $2 \mathrm{ml} \mathrm{min}^{-1}$ (Fig. 2a). For the mutant, however, only one broad peak was obtained (Fig. $2 b$ ). The fraction eluting between 36 and $48 \mathrm{~min}$ from the HPLC column was subjected to mass spectrometry. About 15-20 peaks in the $M_{\mathrm{r}}$ range 800-1200 were obtained in the case of the wild-type, while in the case of the mutant, a number of peaks of significantly lower $M_{\mathrm{r}}(600-850)$ were observed (data not shown).

\section{Discussion}

Earlier studies have indicated that mycolic acid biosynthesis might be the target of some antituberculous drugs (Takayama et al., 1975). We have isolated a mutant of $M$. smegmatis defective in mycolic acid biosynthesis. The 

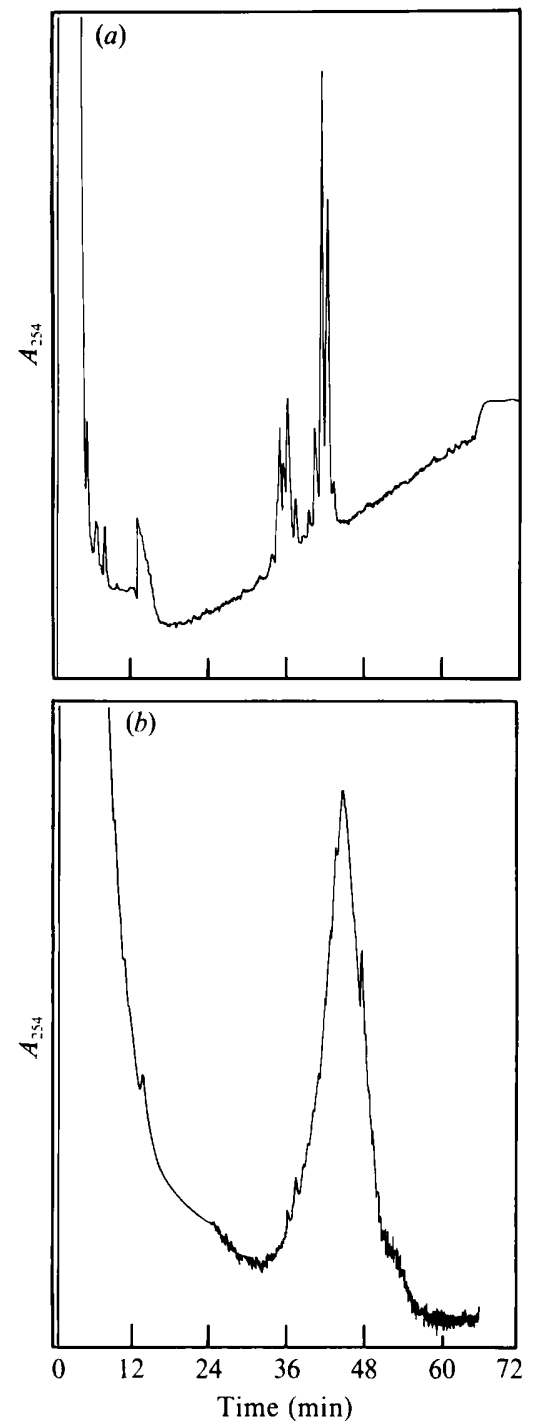

Fig. 2. HPLC profile of $p$-bromophenacyl esters of mycolic acid from (a) wild-type, (b) mutant.

mutant is taxonomically a mycobacterium on the basis of biochemical tests and by the presence of arabinogalactan, a typical cell wall polysaccharide of mycobacteria.

Thin-layer chromatography indicated the absence of methyl mycolates characteristic of $M$. smegmatis. Mass spectrometry of the mycolic acid $p$-bromophenacyl esters revealed the accumulation of shorter-chain fatty acids in the mutant, in contrast to the $\mathrm{C}_{60}-\mathrm{C}_{90}$ fatty acids characteristic of the wild-type. These data suggest that the mutant is defective in mycolic acid biosynthesis.

Biosynthesis of mycolic acids in mycobacteria involves several steps. Elongation and Claisen-like condensation reactions between aliphatic chains occur with several intermediate reactions such as transacylation, carboxylation, reduction, dehydration and desaturation.
In $M$. smegmatis the newly synthesized mycolic acids have been reported to be transferred to final cell wall products via a mycolic acid exchange enzyme (Sathyamoorthy \& Takayama, 1987). However, the biosynthetic machinery responsible for mycolic acid formation remains poorly understood. Qureshi et al. (1978) have identified two structural series of $\mathrm{C}_{28: 1}-\mathrm{C}_{42: 1}$ and $\mathrm{C}_{55: 2}$ meromycolic acids as possible precursors of monoenyl and dienyl mycolic acids respectively, since these acids are structurally related to the $\alpha$-alkylhydroxyl group of the corresponding mycolic acid of $M$. smegmatis (Sathyamoorthy et al., 1985). On the basis of the structures of different precursor fatty acids such as the $\mathrm{C}_{41}, \mathrm{C}_{43}-\mathrm{C}_{56}$ series, a possible pathway covering the precursorproduct relationship between the $\mathrm{C}_{24}-\mathrm{C}_{56}$ fatty acids and $\alpha$-mycolic acids has been proposed by Takayama $\&$ Qureshi (1984). In this scheme $\mathrm{C}_{24-32}$ esters undergo a series of reactions involving elongation, desaturation and cyclopropane ring formation to yield the $\alpha$-meromycolic acid esters $\left(\mathrm{C}_{52}\right.$ or $\mathrm{C}_{54}$ esters). These products serve as the alkyl acceptor in the subsequent condensation reaction with another molecule of $\mathrm{C}_{24}$ or $\mathrm{C}_{26}$ fatty acid ester. However, present knowledge is not sufficient to establish a rigid relationship among the steps of the proposed pathway described above. The accumulation of shorter-chain fatty acids, possibly the precursors of mycolic acids, in the mutant suggests a block in the condensation between $\mathrm{R}_{1}-\mathrm{COOH}$ (meromycolic acids) and the $\alpha$-carbon of a $\mathrm{C}_{24}-\mathrm{C}_{26}$ fatty acid. The purification, and subsequent characterization by mass spectrometry, of the individual components accumulating in the mutant will therefore be very useful in future studies involving detailed characterization of the intermediates present and their final conversion into mycolic acids. This will help to establish the different steps in the proposed pathway of mycolic acid biosynthesis.

\footnotetext{
The authors acknowledge the support received from the United Nations Development Programme, the World Health Organization, and the Department of Science and Technology, Government of India. M. K. and J. B. are Research Associates of the Council of Scientific and Industrial Research, Government of India. The constructive suggestions and help received from Dr Kuni Takayama, Veterans Hospital, Madison, USA, are gratefully acknowledged. We also thank Dr Arun Dutta, Veterans Hospital, Madison, USA, for help in performing some of the experiments.
}

\section{References}

Bloch, K. \& Vance, D. (1977). Control mechanisms in the biosynthesis of saturated fatty acids. Annual Review of Biochemistry 46, 263-298

BUTLER, W. R. \& KILBURN, J. O. (1988). Identification of major slowly growing pathogenic mycobacteria and Mycobacterium gordonae by high performance liquid chromatography of their mycolic acids. Journal of Clinical Microbiology 26, 50-53. 
Butler, W. R., Ahearn, D. G. \& Kilburn, J. O. (1986). High performance liquid chromatography of mycolic acids as a tool in the identification of Corynebacterium, Nocardia, Rhodococcus and Mycobacterium species. Journal of Clinical Microbiology 23, 182185.

DAvid, H. L. (1977). Alkaline phosphatases from Mycobacterium smegmatis. Journal of General Microbiology 101, 99-102.

Gray, G. R., Wong, M. Y. H... \& Danielson, S. J. (1982). The major mycolic acids of Mycobacterium smegmatis. Progress in Lipid Research 21, 91-107.

Kaneda, K., Imaizumi, S., Mizuno, S., Baba, T., Tsukamura, M. \& YANO, I. (1988). Structure and molecular species composition of the three homologous series of $\alpha$-mycolic acids from Mycobacterium spp. Journal of General Microbiology 134, 2213-2229.

Kundu, M., Basu, J. \& Chakrabarti, P. (1989). Purification and characterization of an extracellular lectin from Mycobacterium smegmatis. FEBS Letters 256, 207-210.

Lacave, C., LanÉelle, M. A. \& Lanéelle, G. (1990). Mycolic acid synthesis by Mycobacterium aurum cell free extracts. Biochimica et Biophysica Acta 1042, 315-323.

Lanéelle, M. A., LaCave, C., Daffé, M. \& Lanéelle, G. (1988). Mycolic acids of Mycobacterium aurum, structure and biogenetic implications. European Journal of Biochemistry 177, 631-635.

Matula, M., Mitchell, M. \& Elbein, A. D. (1971). Partial purification and properties of a highly specific trehalose phosphate phosphatase from Mycobacterium smegmatis. Journal of Bacteriology 107, 217-222.

MinNikin, D. E. \& Goodfellow, M. (1980). Lipid composition in the classification and identification of acid-fast bacteria. In Microbiological Classification and Identification, pp. 198-250. Edited by $\mathbf{M}$. Goodfellow \& R. G. Board, London: Academic Press.
Minnikin, D. E., Hutchinson, I. G., Caldicott, A. B. \& GoodfelLow, M. (1980). Thin-layer chromatography of methanolysates of mycolic acid containing bacteria. Journal of Chromatography 188, 221-233.

Qureshi, N., Takayama, K., Jordi, H. C. \& Schnoes, H. K. (1978). Characterization of the purification components of a new homologous series of $\alpha$-mycolic acids from Mycobacterium tuberculosis H37RA. Journal of Biological Chemistry 253, 5411-5417.

RATLEDGE, C. (1982). Lipids: cell composition, fatty acid biosynthesis In The Biology of Mycobacteria, vol. 1, pp. 55-93. Edited by $\mathrm{C}$. Ratledge \& J. Stanford. London: Academic Press.

Sathyamoorthy, N. \& Takayama, K. (1987). Purification and characterisation of a novel mycolic acid exchange enzyme from Mycobacterium smegmatis. Journal of Biological Chemistry 262, $13417-13423$

Sathyamoorthy, N., Qureshi, N. \& Takayama, K. (1985). Purification and characterization of $\mathrm{C}_{28-55}$ fatty acids from Mycobacterium smegmatis. Canadian Journal of Microbiology 31, 214-219.

Steck, P. A., Schwartz, B. A., Rosendahl, M. S. \& Gray, G. A. (1978). Mycolic acids. A reinvestigation. Journal of Biological Chemistry 253, 5625-5629.

Takayama, K., \& QURESHI, N. (1984). Structure and synthesis of lipids. In The Mycobacteria, a Source Book, part A, pp. 315-344. Edited by G. P. Kubica \& L. G. Wayne. New York: Marcel Dekker.

Takayama, K., Schaarves, H. K., Armstrong, E. L. \& Boyle, R. W. (1975). Site of inhibitory action of isoniazid in the synthesis of mycolic acids in Mycobacterium tuberculosis. Journal of Lipid Research 16, 308-317.

US Department of Health and Human Services (1980). Standard taxonomic tests. In Mycobacterial Culture Collection (NIH Publication no. 80-289), pp. 220-239. 